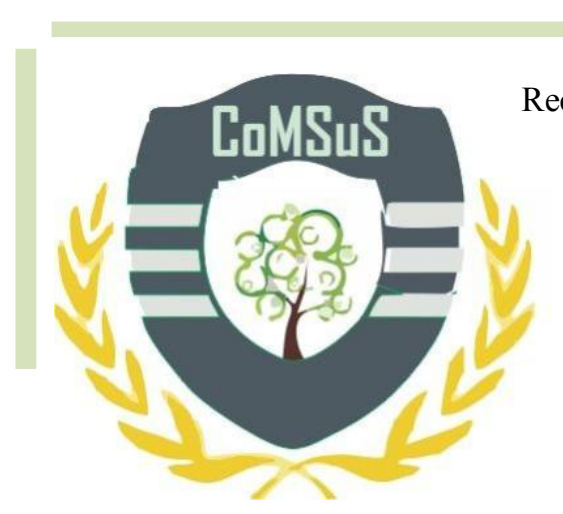

Recebido em 07/03/2018. Aprovado em 07/06/2018. Publicado em 08/11/2018.

Editor: Dr. Ivano Ribeiro

Processo de Avaliação: Double Blind Review - SEER/OJS

e-ISSN: $2359-5876$

https://doi.org/10.5935/2359-5876.20180003

\title{
ESTUDO DA BIOMASSA COMO ENERGIA RENOVÁVEL NO BRASIL A PARTIR DA MATRIZ SWOT
}

\section{STUDY OF THE BIOMASS AS RENEWABLE ENERGY IN BRAZIL FROM THE SWOT FRAMEWORK}

\section{RESUMO}

Luana Teixeira Sousa ${ }^{1}$ Mariana Ferreira de Carvalho Chaves ${ }^{2}$ Silvia Parreira Tannús ${ }^{3}$ José Waldo Martínez Espinosa ${ }^{4}$

A preocupação com a segurança energética e com as questões ambientais ressaltam a importância do uso de energias renováveis, como a biomassa. O Brasil possui um grande potencial para a produção desse tipo de energia, devido ao clima favorável e a grande extensão territorial. Este artigo tem como objetivo principal avaliar o uso de biomassa na matriz energética brasileira. Para tanto foi utilizado a matriz SWOT, a fim de evidenciar as potencialidades e fragilidades da utilização dessa fonte alternativa de energia. Com a aplicação dessa ferramenta, foi possível explorar os variados aspectos da utilização da biomassa, que mostraram que o Brasil possui mais pontos fortes do que fracos, e que apesar disso, sua viabilidade ainda é questionada. Os resultados demostraram que alguns aspectos devem ser reestruturados, a fim de alavancar sua participação na matriz energética.

Palavras-Chave: Energia; Renovável; SWOT.

\begin{abstract}
Concern about energy security and environmental issues highlights the importance of the use of renewable energy, such as biomass. Brazil has a great potential for the production of this type of energy, due to the favorable climate and the great territorial extension. This article aims to evaluate the use of biomass in the Brazilian energy matrix. For this purpose, the SWOT matrix was used in order to highlight the potentialities and weaknesses of the use of this alternative energy source. With the application of this tool, it was possible to explore the various aspects of biomass utilization, which showed that Brazil has more strengths than weak ones, and despite that, its viability is still questioned. The results demonstrated that some aspects must be restructured in order to leverage their participation in the energy matrix.
\end{abstract}

Keywords: Energy; Renewable; SWOT.

${ }^{1}$ Graduanda de Engenharia de Produção pela Universidade Federal de Goiás - Regional Catalão - GO. E-mail: luanatssousa@gmail.com

2 Graduanda de Engenharia de Produção pela Universidade Federal de Goiás - Regional Catalão - GO. E-mail: marianafcchaves20@gmail.com

${ }^{3}$ Doutora em Economia Aplicada pela Universidade Federal de Uberlândia - UFU. Professora do Curso de Engenharia de Produção na Universidade Federal de Goiás - Regional Catalão - GO. E-mail: silviaparreira@yahoo.com.br

${ }^{4}$ Doutor em Ciência e Engenharia dos Materiais pela Universidade Federal de São Carlos - UFSCar. Professor do Curso de Engenharia de Produção na Universidade Federal de Goiás - Regional Catalão - GO. E-mail: jowa198@hotmail.com 


\section{INTRODUÇÃO}

A maior parte da oferta energética mundial do século XXI é baseada em fontes não renováveis. Com as grandes mudanças climáticas decorrentes das emissões de gases de efeito estufa, as energias renováveis, aquelas em que os recursos naturais utilizados na produção são de fácil regeneração, aparecem como uma grande alternativa para essa crise ambiental.

Nesse contexto de preocupações com mudanças climáticas e segurança energética, a implantação de fontes renováveis é fundamental. Há inúmeros benefícios, se implantados de maneira adequada, que vão desde a contribuição para o desenvolvimento social e econômico, até a universalização do acesso à energia e a redução de efeitos nocivos ao meio ambiente e à saúde. As políticas para promoção de pesquisa, desenvolvimento e implantação de fontes renováveis, geralmente, são classificadas em três categorias: incentivos fiscais, mecanismos estatais de financiamento e políticas regulatórias (Intergovernmental Panel On Climate Change [IPCC], 2011, Instituto de Economia Agrícola [IEA], 2011 como citado em Uczai, 2012).

$\mathrm{O}$ ingresso da biomassa no mercado energético depende de vários fatores, como: a exploração adequada da componente energética e de um planejamento detalhado sobre a geologia e o clima da área de produção, das fontes potenciais, das necessidades energéticas locais e da degradação na área. No Brasil, mesmo que a geração de energia elétrica provenha principalmente do potencial hidráulico, a grande extensão territorial e o clima tropical que domina quase todo o território, possibilitam excelentes condições para a produção e o uso energético da biomassa, que é a matéria orgânica, como cana-deaçúcar, lenha, carvão vegetal e óleos vegetais, que são utilizados na produção de energia a partir de processos como a combustão (Colantoni, Delfanti, Recanatesi, Tolli \& Lord, 2015).

Segundo dados do Balanço Energético Nacional (Brasil. Empresa de Pesquisa Energética EPE, 2016), a participação da biomassa na matriz energética brasileira (oferta interna de energia elétrica por fonte) é de $8,0 \%$, enquanto que a hidráulica é $64,0 \%$, gás natural $12,9 \%$, derivados do petróleo $4,8 \%$, carvão e derivados $4,5 \%$, eólica $3,5 \%$, nuclear $2,4 \%$ e solar $0,01 \%$. A atuação da biomassa na matriz energética é pequena em vista das outras fontes, devido à falta de incentivo e de processos economicamente viáveis.

O objetivo principal desse estudo é avaliar, por meio da matriz SWOT, as potencialidades, vantagens, desvantagens e fragilidades da utilização da biomassa como fonte de energia renovável, a fim de analisar suas ações na participação da matriz energética, com foco central na questão ambiental.

\section{REVISÃO BIBLIOGRÁFICA}

\subsection{Biomassa}

O Banco de Informações de Geração (BIG) da ANEEL (2017) afirma que o país investe nos seguintes tipos de combustíveis para geração de energia por meio da biomassa: carvão vegetal, resíduos da madeira, bagaço de cana-de-açúcar, casca de arroz, licor negro, biogás, capim elefante e óleo de palmiste (óleo vegetal comestível derivado da amêndoa da palma). O maior potencial energético é do bagaço de cana-de-açúcar, $11.042 .010 \mathrm{~kW}$, equivalente a 79,06\%, seguido pelo licor negro de potência igual a $2.261 .136 \mathrm{~kW}, 16,19 \%$ do total.

De acordo com Martins (2014) há três tipos de biomassa: sólida, biocombustíveis gasosos e biocombustíveis líquidos. A biomassa sólida é proveniente de produtos e resíduos agrícolas, florestais e das indústrias e a fração biodegradável dos resíduos industriais e urbanos. Os biocombustíveis gasosos são oriundos da degradação anaeróbia da matéria orgânica contida nos efluentes agropecuários, da agroindústria e urbanos (lodos das estações de tratamento dos efluentes domésticos) e ainda nos aterros de Resíduos Sólidos Urbanos e é constituído por uma mistura de metano $\left(\mathrm{CH}_{4}\right)$, em percentagens que variam entre os $50 \%$ e os $70 \%$, sendo o restante essencialmente $\mathrm{CO}_{2}$. Enquanto que os biocombustíveis líquidos são obtidos a partir de óleos in natura, da fermentação de hidratos de carbono (etanol) e de óleos vegetais.

Em termos industriais, Xu et al. (2016) estudaram a produção industrial de energia elétrica 
utilizando diferentes tipos de biomassa, correlacionando também os efeitos nocivos que podem ser gerados com diferentes tecnologias na produção de eletricidade a partir de biomassa. Cada tipo de biomassa possui um processo de conversão para produzir energia elétrica. Os processos de conversão utilizados são:

- Fermentação: esse processo químico requer a existência de micro-organismos para fermentar o açúcar em álcool, acido láctico e outros produtos finais. Caracteriza-se por ser uma reação natural e biológica que depende das condições da matéria (Chandel et.al., 2007, Wheals et.al., 1999 como citado em Limayem \& Ricke, 2011).

- A liquefação: é a transformação da biomassa e outras fontes fósseis de carbono em produtos predominantemente líquidos podendo ser de forma direta ou indireta. Esta última baseia-se em produzir gás $\mathrm{CO}+\mathrm{H}_{2}$ por gaseificação e, utilizando um catalisador, transformá-lo em metanol ou hidrocarboneto. Porém, a processo direto é proveniente da atmosfera redutora de hidrogênio ou da mistura de hidrogênio e monóxido de carbono, sendo, assim, considerada uma forma de pirólise. Nesse processo a biomassa forma uma suspensão com $10 \%$ a $30 \%$ ao ser triturada em uma faixa granulométrica e misturada com algum solvente (Boyles, 1984; Soltes, 1986, Rocha, 1997 como citado em GBio, 2015c).

- Combustão Direta: é uma interação entre combustível, energia e o ambiente. Baseia-se na queima do material sólido produzindo calor e energia. Essa queima é realizada principalmente em fornalhas, dispositivos projetados para certificar a total queima do material de maneira eficiente e contínua (Lippel, 2017; Shafizadeh, 1981).

- Cogeração: é a produção simultânea de energia térmica e mecânica a partir de uma mesma fonte primária de energia. A energia mecânica pode ser utilizada na forma de trabalho e a energia térmica é utilizada como fonte de calor para processos em geral (GBio, 2015c).

- Pirólise: a reação se baseia na decomposição térmica dos componentes orgânicos a uma temperatura que varia de $400{ }^{\circ} \mathrm{C}$ a $600{ }^{\circ} \mathrm{C}$ em uma atmosfera isenta de oxigênio, tendo como resultados o carvão, o óleo e produtos gasosos (Antonakou et al., 2006 como citado em Wang et al., 2015).

- Gaseificação: é um processo químico no qual, por meio de um comburente, podendo ser oxigênio, ar, dióxido de carbono ou vapor, uma matéria-prima sofre reação de oxidação parcial. Tal processo é composto por etapas, sendo elas: secagem, pirólise, gaseificação e combustão. O produto final é composto por fases sólida, líquida e gasosa, isto depende da matéria-prima e das condições do processo químico, como a temperatura e a pressão (Corella et al., 2008 como citado em Nemanova, Abedini, Liliedahl \& Engvall, 2013).

- Craqueamento: é a formação de uma mistura de compostos químicos com propriedades muito semelhantes às do diesel a partir da quebra das moléculas do óleo e gordura. Tal mistura pode ser usada em motores convencionais do ciclo diesel, sendo que esta reação é efetuada a altas temperaturas com a presença ou a ausência de catalisadores (Suarez, 2005 como citado em GBio, 2015c).

- Transesterificação: é uma reação que também é conhecida como alcoolização, consiste na reação de óleos vegetais com um produto intermediário ativo, sendo um processo similar à hidrólise, exceto que utiliza um álcool, metanol ou etanol, ao invés de água. Tem como resultado moléculas de triglicérides, que são transformadas em ésteres menores conhecido como óleo diesel ou biodiesel (Encinar et al., 2002, Quik et al, 1983 como citado em Gude \& Martinez-Guerra, 2014; Liu, Tu, Knothe \& Lu, 2017; Ribeiro et al., 2001 como citado em GBio, 2015c).

Esse processo químico pode ser realizado utilizado catalisadores homogêneos ou heterogêneos. Catalisadores homogêneos, como hidróxido de sódio ou hidróxido de potássio, produzem durante o processo de separação do biodiesel, quantidades de águas residuais que são prejudiciais ao meio ambiente. Todavia, catalisadores heterogêneos têm como vantagem a não corrosividade e podem ser considerados benignos para o ecossistema (Di Serio et al., 2007, Sivasamy 2009 como citado em Gude \& Martinez-Guerra, 2014; Liu et al., 2017; Ribeiro et al., 2001 como citado em GBio, 2015c).

A questão da sustentabilidade da biomassa é de especial importância, principalmente, nos países em desenvolvimento. Em muitos países, a biomassa tradicional é a fonte de energia mais utilizada para cocção e aquecimento de ambientes, principalmente por questões 
econômicas; porém, deve ser utilizada de maneira correta, evitando impactos negativos à saúde humana e ao meio ambiente (Guardabassi, 2006).

Tento isso em mente, Suresh, Singh, Malik, Datta e Pal (2016) realizaram um estudo comparativo sobre o uso de vários tipos de combustíveis, incluindo a biomassa sólida, para uso doméstico. Encontraram que a eficiência térmica de fogões com diferentes tipos de combustíveis de biomassa sólida variam. De forma análoga, Islam, Khanam, Rouf e Rahaman (2014) efetuaram uma investigação sistemática da transferência de calor e do rendimento de combustão em fogões domésticos, usando tecnologias modificadas que ajudam a garantir melhoria significativa sobre métodos tradicionais de cozinha com biomassa.

Entretanto, um falho sistema de produção e uso de fontes renováveis pode afetar o meio ambiente assim como os combustíveis fósseis (Colantoni et al., 2015). Assim, o Ciclo Brasil, um programa integrado de aproveitamento de resíduos, tem como objetivo central reduzir os desperdícios e os impactos ambientais, impulsionar o crescimento econômico e propiciar novas oportunidades de trabalho. Uma das propostas é criação de conglomerados, ou seja, grupo de moradores ao redor das empresas da região, a fim de serem incentivados e treinados para 0 aproveitamento rentável dos resíduos, gerando novas alternativas e fontes de renda. Lembrando que, o conceito de resíduo para essas entidades é tudo que se pode agregar valor, provocando uma nova cadeia produtiva (Grauer \& Kawano, 2008).

\subsection{Matriz SWOT}

A análise SWOT, acrônimo para Strenghts, Weaknesses, Opportunities e Threats, em português: Forças, Fraquezas, Oportunidades e Ameaças (matriz FOFA), consiste em uma metodologia popular no âmbito empresarial (Rosa, 2013). Desenvolvida entre as décadas de 1960 e 1970, é um sistema utilizado como base para a gestão e o planejamento estratégico de empresas, ou neste caso, de segmento independente do seu porte. É uma análise muito útil, proporcionando uma visão interna e externa do negócio, além de identificar os elementos-chaves para a gestão a fim de estabelecer as prioridades de atuação. A principal função da análise SWOT é possibilitar a escolha de uma estratégia adequada, a fim de alcançar os objetivos da organização. Deve ser aplicada de tempos em tempos, já que fornece dados essenciais para o planejamento estratégico da empresa.

Segundo Tavares (2005) a análise SWOT é uma forma simples de expor e contrapor as variáveis em questão, sendo que as forças e fraquezas representam as competências internas da entidade tomadora de decisão, que deve conhecer para posicionar-se frente às alternativas. E as oportunidades e ameaças são os fatores externos, que se deve conhecer para aproveitar, evitar ou enfrentar, visando um melhor resultado. 
Figura 1. Matriz SWOT.

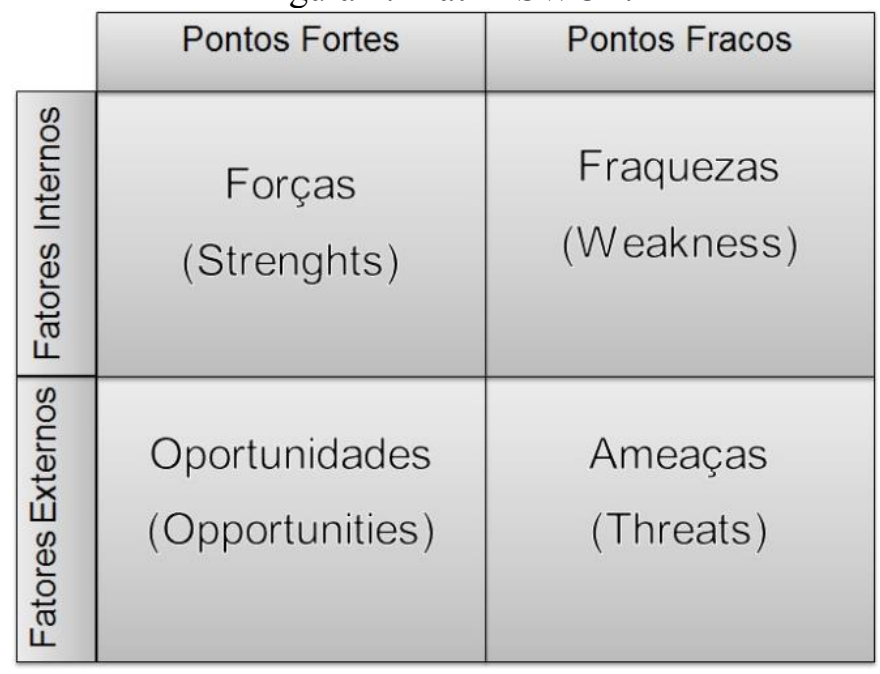

Fonte: Adaptada pelos autores

Como visualizado na figura 1, a matriz SWOT é baseada em um quadro com dois eixos horizontais compostos pelos dados internos da organização e do ambiente externo e dois eixos verticais que correspondem aos aspectos positivos e negativos da própria organização. Para criar uma matriz SWOT é preciso dividir o cenário empresarial ou do segmento, nesse caso, e levantar o maior número possível de itens para cada área analisada. No ambiente interno são determinadas as forças que são as vantagens em relação aos concorrentes, que aumentam sua competitividade e fraquezas que consiste nas aptidões que interferem no bom andamento do negócio. Já no ambiente externo, são estabelecidas as oportunidades que são forças externas que influenciam positivamente a empresa e ameaças, forças externas que influenciam negativamente a organização.

Nakagawa (2012) ressalta a importância da avaliação das informações apresentadas na matriz visando a imparcialidade e maior confiabilidade das informações. Verificadas as informações, faz-se necessária a elaboração de um plano de ação para minimizar as fragilidades e impulsionar os pontos fortes.

\section{METODOLOGIA}

Quanto ao objetivo, trata-se de uma pesquisa descritiva por realizar observações sistemáticas do processo selecionado para o estudo, a fim de conhecer as características do mesmo (Santos, 2004). A respeito da abordagem de pesquisa, classifica-se como qualitativa uma vez que não é feita a coleta de dados com instrumentos estruturados e há enfoque na compreensão do fenômeno e nos conceitos específicos relacionados (Fantinato, 2015).

Com o propósito de atender o objetivo do estudo, nesse caso avaliar a utilização da biomassa como fonte de energia renovável, utilizou-se a matriz SWOT. Empregou-se essa metodologia com o intuito de expor e contrapor os dados levantados a fim de formar futuras estratégias para minimizar os pontos fracos, amparar nos pontos fortes, antecipar-se perante as ameaças e alavancar a partir das oportunidades oferecidas pelo setor.

Quanto ao procedimento técnico, realizou-se pesquisa bibliográfica que é feita a partir do levantamento de referências teóricas publicadas em meios escritos e eletrônicos (Fantinato, 2015). As informações e dados utilizados foram coletados a partir de relatórios publicados pela CENBIO (Centro Nacional de Referência em Biomassa), GBio (Grupo de Pesquisa em Bioenergia) do IEE (Instituto de Energia e Ambiente), IEA (Instituto de Economia Agrícola), BEN (Balanço Energético Nacional), ANEEL (Agência Nacional de Energia Elétrica), além de dados do Ministério de Minas e Energia. O período de análise foi entre 1980 e 2017. 


\section{RESULTADOS E DISCUSSÕES}

Posterior à identificação das formas de sintetização da biomassa e quais são as mais utilizadas, realizou-se a análise da matriz SWOT para esse tipo de matéria. A partir desta síntese, poderão ser formadas estratégias a fim de firmar os pontos fortes, minimizar os pontos fracos, prevenir-se das ameaças e explorar as oportunidades do setor.

Figura 2. Análise SWOT do uso de biomassa da década de 1980 até 2017.

\begin{tabular}{|l|l|}
\hline \multicolumn{1}{|c|}{ Forças } & \multicolumn{1}{c|}{ Fraquezas } \\
\hline - Baixo custo de aquisição; & \\
- Minimiza os custos de transmissão; & $\begin{array}{l}\text {-Dificuldades no transporte e armazenamento } \\
\text { de biomassa sólida. }\end{array}$ \\
- Permite o reaproveitamento de residuos. & \\
\hline \multicolumn{1}{|c|}{ Oportunidades } & \\
\hline $\begin{array}{l}\text { - Redução da dependência de recursos não } \\
\text { renováveis; } \\
\text { - Menor impacto ambiental do que as outras } \\
\text { fontes termelétricas tradicionais; } \\
\text { - Compensação do dióxido de carbono emitido } \\
\text { na combustão da biomassa; } \\
\begin{array}{l}\text { - Emissões de gases e outras substâncias } \\
\text { nocivas provenientes da decomposição dos } \\
\text { residuos do processamento da biomassa. }\end{array}\end{array}$ & $\begin{array}{l}\text { - Maior possibilidade de geração de material } \\
\text { particulado para a atmosfera; }\end{array}$ \\
\hline
\end{tabular}

Fonte: Dados da pesquisa

\subsection{Pontos fortes}

As vantagens econômicas da biomassa, principalmente para os países em desenvolvimento, baseiam-se no fato de ser uma fonte de energia produzida regionalmente e, portanto, colabora com a independência energética e geração de receita. No caso do Brasil, a maior parte dos equipamentos necessários para a conversão da biomassa em energia é de fabricação nacional, logo não há necessidade de importação, como ocorre como outras fontes de energia (GBio, 2015b).

Os resíduos florestais apresentam um grande potencial, considerando todos os materiais orgânicos encontrados na floresta como sobras de madeira, folhas, raízes, serapilheira, galhos e casca. Segundo a Atlas de Biomassa Residual do Brasil, desenvolvido pela Associação Brasileira das Indústrias de Biomassa e Energia Renovável, o país possui um potencial de resíduos florestais de $157.992 .556 \mathrm{~m}$ e para a geração de energia térmica tem 1.244.253 TJ (Oliveira, 2012).

No começo do século XXI, o setor madeireiro experimentou um salto tecnológico surpreendente, que resultou no aprimoramento das técnicas de implantação, manejo e exploração. Todo esse desenvolvimento qualifica o setor para o aproveitamento da biomassa sem promover o desflorestamento. Surge, então, a possibilidade de desenvolvimento genético de espécies (principalmente de culturas de rápido crescimento que propiciem cortes em curtos períodos de tempo), 
de técnicas, de processos e de equipamentos de produção específicos para atender às demandas de uso energético, como a complementação da sazonalidade de diferentes culturas a fim de garantir combustível durante o ano inteiro (Cruz \& Nogueira, 2004).

\subsection{Pontos fracos}

As empresas têm dificuldades para transportar e armazenar a biomassa. O transporte é feito via rodovias, sendo assim, há gastos com o combustível utilizado e com o desgaste do veículo ao longo do tempo. Além disso, os combustíveis em sua forma bruta não possuem condições favoráveis de transporte e manipulação, por não terem granulometria adequada. Quanto à armazenagem, a biomassa geralmente absorve a umidade se for exposta e dessa maneira pode biodegradar, isso leva a perca do potencial energético e a formação de fungos e bolores. Ademais, a biomassa não escoa tão livremente quanto o óleo ou o gás natural (Fernandes et al., 2012; Lippel, 2014).

\subsection{Oportunidades}

O país necessita estudar as condições socioeconômicas e ambientais que influenciam diretamente no setor de biomassa. A biomassa pode ser considerada uma fonte energética primária, já que os materiais ou produtos obtidos são diretamente da natureza, como a lenha e a cana-de-açúcar, ao contrário das secundárias, que são combustíveis resultantes de processos de conversão dos combustíveis energéticos primários. Pode-se citar o carvão vegetal que é produzido a partir da madeira e o álcool que é feito a partir de substancias fermentáveis (Nogueira \& Lora, 2003 como citado em GBio, 2015a).

Quando produzida de maneira eficiente e sustentável, a energia da biomassa traz inúmeros benefícios ambientais, econômicos e sociais quando comparados aos combustíveis fósseis. As vantagens econômicas da biomassa baseiam-se principalmente no fato de ser uma fonte de energia produzida regionalmente, o que impulsiona a geração de receita, a independência energética e criação de novos empregos. Esses benefícios incluem também o melhor manejo da terra, o uso de áreas agrícolas excedentes nos países industrializados, a redução nos níveis de emissões de $\mathrm{CO}_{2}$, o controle e reaproveitamento de resíduos, a flexibilidade de suprir energéticos tanto para a produção de energia elétrica quanto para mover o setor de transportes (GBio, 2015b).

Do ponto de vista social, a geração de empregos diretos e indiretos tem sido reconhecida como um dos principais benefícios da biomassa. Apesar da maior parte da mão-de-obra exigida ser não qualificada, promove um ciclo virtuoso nas regiões de produção agrícola, caracterizado, principalmente, pelo aumento dos níveis de consumo e qualidade de vida, inclusão social, geração de novas atividades econômicas, fortalecimento da indústria local, promoção do desenvolvimento regional e redução do êxodo rural (ANEEL, 2008, p. 74).

\subsection{Ameaças}

Apesar das plantações serem uma opção final, a madeira, biomassa primária, vem sendo utilizada como principal matéria para produção de energia devido ao baixo custo. $\mathrm{O}$ tipo de produção de madeira, extrativista ou reflorestamento, influi diretamente na distribuição espacial dos resíduos gerados. Nos casos de extração seletiva e beneficiamento descentralizado, o aproveitamento de resíduos pode se tornar inviável economicamente. $\mathrm{O}$ uso de madeira remete a muitos a insustentabilidade e à insuficiência, contudo, apenas os polos presentes em Pará, Mato Grosso e Rondônia usam a madeira nativa devido à dificuldade de acesso à eletricidade (ANEEL, 2005; Freitas, 2013; Macedo, 2001).

Devido às características físico-químicas e biológicas, a biomassa residual necessita passar por um tratamento adequado antes de sua disposição final, visando à redução do seu potencial poluidor. Quando a biomassa residual é lançada diretamente na água, causa inúmeros problemas que 
comprometem a qualidade dos recursos hídricos e colabora diretamente para o desequilíbrio ambiental. A água possui a capacidade de diluir e assimilar a carga orgânica presente na biomassa, sendo essa degradação realizada por organismos aeróbicos que consomem o oxigênio disponível na água. Quando existe abundância de matéria orgânica, cresce o número de indivíduos que atuam na degradação da mesma e pode-se chegar a um processo dinâmico de eutrofização artificial, em que há falta de oxigênio no corpo hídrico e aumento da concentração de nutrientes, principalmente fósforo e nitrogênio (Fernandes et al., 2012).

Durante a produção de energia com a queima de biomassa, ocorre uma intensa produção de poluentes atmosféricos e entre eles está o material particulado fino e o grosso. Tais materiais são considerados nocivos à saúde humana e fatores de risco para doenças respiratórias. Outro fator visto como ameaça é o baixo poder calorífico da biomassa. Para contornar esse defeito, precisa-se aumentar a eficiência de conversão, melhorar as pressões de operação e utilizar turbinas mais eficientes (Macedo, 2001; Silva, 2010).

\section{CONSIDERAÇÕES FINAIS}

A partir da avaliação da utilização da biomassa no Brasil por meio da matriz SWOT, percebeuse que essa fonte apresenta mais pontos fortes do que fracos, mas apesar disso, as fraquezas pesam o suficiente para questionar a viabilidade da biomassa. Esse material tem como principais obstáculos o baixo poder calorífico, a dificuldade do transporte e armazenamento e o desmatamento proveniente do uso da madeira nativa. Essas ameaças devem ser reestruturadas a fim de se tornarem oportunidades e alavancar sua participação no mercado interno.

Durante a combustão da biomassa, processo mais utilizado na conversão desse material em energia, há transmissão de $\mathrm{CO}_{2}$ ao meio ambiente, e por mais que ele seja compensado ao longo do crescimento da planta, é consideravelmente alto. Ao passo que as constantes preocupações com o ecossistema giram em torno das emissões de gases poluentes, das questões do efeito estufa e do aquecimento global, há a necessidade de mais estudos. Diante disso, é preciso ser feito uma avaliação sistemática do desempenho de cada tipo de biomassa e eficiência do seu processo de conversão, levando em consideração principalmente a biomassa sólida, de acordo com a sua origem e com o seu tamanho, uma vez que é a mais utilizada.

No entanto, mesmo que seja uma das causadoras de risco para o ecossistema devido à produção de $\mathrm{CO}_{2}$ durante a geração de energia, a biomassa é uma fonte de energia elétrica e térmica que expande no país. Com o intuito de aumentar ainda mais sua influência na sociedade, há constantes inovações em tecnologias com o propósito de amenizar o efeito negativo que pode ser promovido por essa matéria, há congressos, como o CIBIO (Congresso Internacional da Biomassa), e programas governamentais.

$\mathrm{O}$ presente estudo mostra relevância tanto no âmbito acadêmico quanto empresarial. $\mathrm{Na}$ área acadêmica, a pesquisa serve como fonte bibliográfica, além de mostrar uma aplicação direta da ferramenta utilizada, a matriz SWOT, fora da esfera organizacional. No campo empresarial, mostra a importância da análise das fontes energéticas utilizadas nos processos produtivos e dos impactos ambientais existentes.

\section{REFERÊNCIAS}

Agência Nacional de Energia Elétrica [ANEEL]. (2005). Atlas de energia elétrica do Brasil (2a ed.). Brasília: ANEEL. Consultado em 25 jun. 2016. Disponível em http://www2.aneel.gov.br/aplicacoes/atlas/pdf/05-Biomassa(2).pdf

Agência Nacional de Energia Elétrica [ANEEL]. (2008). Atlas de energia elétrica do Brasil. ( $3^{\mathrm{a}}$ ed.). Brasília: ANEEL. Consultado em 25 jun. 2016. Disponível em http://www2.aneel.gov.br/arquivos/PDF/atlas3ed.pdf

Agência Nacional de Energia Elétrica [ANEEL]. (2017). BIG - Banco de Informações de 
Geração: Combustivel Biomassa. Brasília: ANEEL. Consultado em 19 jul. 2017. Disponível em http://www2.aneel.gov.br/aplicacoes/capacidadebrasil/CombustivelPorClasse.cfm?Classe=Bio $\underline{\text { massa }}$

Colantoni, A., Delfanti, L., Recanatesi, F., Tolli, M., \& Lord, R. (2016, janeiro). Land use planning for utilizing biomass residues in Tuscia Romana (central Italy): Preliminary results of a multi criteria analysis to createan agro-energy district. Land Use Policy, 50(1), 125-133. Consultado em 19 nov. 2016. doi: 10.1016/j.landusepol.2015.09.012

Cruz, P. de T. de A., \& Nogueira, M.M. (2004, julho). Oportunidades para o desenvolvimento da biomassa energética no Brasil. Revista da Madeira, 82. Consultado em 01 out. 2016. Disponível em

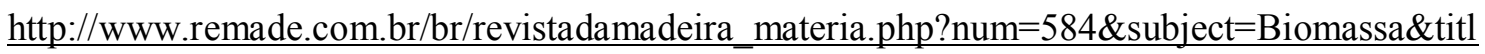
e=Oportunidades

Empresa de Pesquisa Energética (Brasil). (2016). Balanço Energético Nacional 2016: Ano base 2015 / Empresa de Pesquisa Energética (11 ${ }^{\mathrm{a}}$ ed.). Rio de Janeiro: EPE. Consultado em 16 jul. 2017. Disponível em https://ben.epe.gov.br/downloads/Relatorio_Final_BEN_2016.pdf

Fantinato, M. (2015). Métodos de Pesquisa [slide]. São Paulo: PPgSI - EACH - USP, 2015. Consultado em 26 dez. 2016. Disponível em http://each.uspnet.usp.br/sarajane/wpcontent/uploads/2015/09/Métodos-de-Pesquisa.pdf

Fernandes, D.M., Suzuki, A.B.P, Vieira, A.C., Araújo, I.R.C., Costanzi, R.N., Faria, R.A.P., \& Edwiges, T. (2012, janeiro). Biomassa como fonte alternativa de energia. Revista da Madeira, 138. Consultado em 20 fev. 2017. Disponível em http://www.remade.com.br/br/revistadamadeira materia.php?num=1734\&subject=Biomassa $\% 2$ Ofonte $\% 20$ energia\&title $=$ Biomassa $\% 20$ como $\% 20$ fonte $\% 20$ alternativa $\% 20 \mathrm{de} \% 20$ energia

Freitas, S.M. (2013, junho). Brasil Expande a Cogeração de Energia a Partir de Resíduos Agropecuários. Consultado em 25 jun. 2016. Disponível em http://www.iea.sp.gov.br/out/LerTexto.php?codTexto=12655

Grauer, A., \& Kawano, M.(2008, janeiro). Aproveitamento de resíduos para biomassa é rentável. Revista da Madeira, 110. Consultado em 02 out. 2016. Disponível em http://www.remade.com.br/br/revistadamadeira_materia.php?num=1203\&subject=Biomassa

Grupo de Pesquisa em Bioenergia [GBio] (2015a). Fontes de biomassa. Consultado em 25 jun. 2016. Disponível em http://www.iee.usp.br/gbio/?q=livro/fontes-de-biomassa

Grupo de Pesquisa em Bioenergia [GBio]. (2015b). Importância e vantagens da biomassa. Consultado em 26 jun. 2016. Disponível em http://www.iee.usp.br/gbio/?q=livro/importância-e-vantagensda-biomassa

Grupo de Pesquisa em Bioenergia [GBio]. (2015c). Tecnologias de Aproveitamento. Consultado em 26 jun. 2016. Disponível em http://www.iee.usp.br/gbio/?q=livro/tecnologias-deaproveitamento

Islam, M.S., Khanam, M., Rouf, M.A., \& Rahaman, M. (2014, dezembro). Performance evaluation of improved cook stoves (ICS) disseminating in Bangladesh. Bangladesh Journal of Scientific and Industrial Research, 49(4), 219-225. Consultado em 05 out. 2016. doi: 10.3329/bjsir.v49i4.22624

Kupfer, D., \& Hasenclever, L. (2002). Economia Industrial: Fundamentos Teóricos e Práticas no Brasil. Rio Janeiro: Campus.

Limayem, A., \& Ricke, S. C. (2012, agosto). Lignocellulosic biomass for bioethanol production: Current perspectives, potential issues and future prospects. Progress in Energy and Combustion Science, 38(4), 449-467. Consultado em 29 mai. 2017. Disponível em 
https://www.sciencedirect.com/science/article/pii/S0360128512000172

Lippel. (2014). Silos de armazenagem para biomassa. Consultado em 27 jun. 2016. Disponível em http://www.lippel.com.br/br/sustentabilidade/silos-de-armazenagem-para-biomassa\#.V6ps3I$\underline{\mathrm{cHIV}}$

Lippel. (2017). Combustão da biomassa: Construimos geradores de gases quentes que usam biomassa como combustivel natural, para sistemas que necessitam de energia térmica. Consultado em 19 jul. 2017. Disponível em http://www.lippel.com.br/br/combustao-da-biomassa.html

Liu, Y., Tu, Q., Knothe, G., \& Lu, M. (2017, julho). Direct transesterification of spent coffee grounds for biodiesel production. Fuel, 199(1), 157-161. Consultado em 24 jul. 2017. doi:

10.1016/j.fuel.2017.02.094

Macedo, I. C. (2001). Geração de energia elétrica a partir de biomassa no Brasil: situação atual, oportunidades e desenvolvimento. Brasil: Centro de Gestão e Estudos Estratégicos [CGEE]. Consultado em 26 jun. 2016. Disponível em http://www.cgee.org.br/arquivos/estudo003_02.pdf

Martinez-Guerra, E., \& Gude, V. G. (2014, dezembro). Transesterification of used vegetable oil catalyzed by barium oxide under simultaneous microwave and ultrasound irradiations. Energy Conversion and Management, 88(1), 633-640. Consultado em 29 maio 2017. doi: $\underline{10.1016 / j . e n c o n m a n .2014 .08 .060}$

Martins, O.S. (2004). Aproveitamento da Biomassa para a Geração de Energia Elétrica [color slides]. Brasília: Centro Nacional de Referência em Biomassa. Consultado em 24 jun. 2016. Disponível em http://www.eletrobras.gov.br/elb/portal/data/documents/storedDocuments/\{A550763A-377A4EFC-B5F4-7FB3FFD886CB $\} /\{6632 \mathrm{~A} 665-43 \mathrm{~B} 7-4 \mathrm{D} 5 \mathrm{~B}-838 \mathrm{~F}-$ E2283345D2D2\}/1\%B0Semin\%E1rioFRE_ANEEL_CENBIO_Biomassa_041209.pdf

Nemanova, V., Abedini, A., Liliedahl, T., \& Engvall, K. (2014, janeiro). Co-gasification of petroleum coke and biomass. Fuel, 117(Part A), 870-875. Consultado em 29 maio 2017. doi: 10.1016/j.fuel.2013.09.050

Oliveira, C. (2012, fevereiro). Futuro da biomassa no Brasil. Revista da Madeira, 130. Consultado em 20 fev. 2017. Disponível em http://www.remade.com.br/br/revistadamadeira_materia.php?num=1583\&subject=Biomassa\&ti tle $=$ Futuro $\% 20 \mathrm{da} \% 20$ biomassa $\% 20$ no $\% 20$ brasil

Rosa, C. A. (Org.). (2013). Como elaborar um plano de negócios. Brasília: Serviço Brasileiro de Apoio às Micro e Pequenas Empresas [Sebrae]. Consultado em 08 jul. 2016. Disponível em http://www.sebrae.com.br/Sebrae/Portal Sebrae/Anexos/COMO ELABORAR UM PLANO baixa.pdf

$\underline{\text { Santos, Antonio Raimundo dos. (2004). Metodologia científica: a construção do conhecimento }\left(6^{\mathrm{a}}\right.}$ ed.). Rio de Janeiro: DP\&A.

Sasson, J. M. (2011). Biomassa: uma dupla solução. Consultado em 10 jul. 2016. Disponível em https://www.ambienteenergia.com.br/index.php/2011/06/biomassa-uma-dupla-solucao/11991

Shafizadeh, F. (1981). Basic Principles of Direct Combustion. In S.S. Sofer \& O.R. Zaborsky (Eds), Biomass Conversion Processes for Energy and Fuels (pp. 103-124). Consultado em 19 jul. 2017. doi: 10.1007/978-1-4757-0301-6_6

SILVA, A. M. C. da, Mattos, I.E., Freitas, S.R., Longo, K.M., \& Hacon, S.S. (2010). Material particulado $\left(P M_{2.5}\right)$ de queima de biomassa e doenças respiratórias no sul da Amazônia brasileira. Revista Brasileira de Epidemiologia, 13(2), 337-351. Consultado em 10 jul. 2016. Disponível em http://www.scielosp.org/pdf/rbepid/v13n2/15.pdf 
Suresh, R., Singh, V.K., Malik, J.K., Datta, A., \& Pal, R.C. (2016, dezembro). Evaluation of the performance of improved biomass cooking stoves with different solid biomass fuel types. Biomass And Bioenergy, 95(1), 27-34. Consultado em 05 out. 2016. doi: 10.1016/j.biombioe.2016.08.002

Tavares, M. C. (2005). Gestão Estratégica (2a ed.). São Paulo: Atlas.

Uczai, P. (Coord.). (2012). Energias Renováveis: riqueza sustentável ao alcance da sociedade. Brasília: Câmara do Deputados. Consultado em 08 jul. 2016. Disponível em http://www2.camara.leg.br/a-camara/altosestudos/pdf/energias-renovaveis-riqueza-sustentavelao-alcance-da-sociedade

Wang, N., Tahmasebi, A., Yu, J., Xu, J. Huang, F., \& Mamaeva, A. (2015, abril). A Comparative study of microwave-induced pyrolysis of lignocellulosicand algal biomass. Bioresource Technology, 190(1), 89-96. Consultado em 29 maio 2017. doi: 10.1016/j.biortech.2015.04.038

Xu, C., Hong, J., Chen, J., Han, X., Lin, C., \& Li, X. (2016, outubro). Is biomass energy really clean? An environmental life-cycle perspective on biomass-based electricity generation in China. Journal Of Cleaner Production, 133, 767-776. Consultado em 05 out. 2016. Disponível em https://www.sciencedirect.com/science/article/pii/S0959652616306606 